\title{
Cerebrospinal fluid - cutaneous fistula after lumbar epidural for labour analgesia - Case Report
}

Alves, DR ${ }^{1}$; Silva, B ${ }^{2}$; Aquino, E ${ }^{2}$; Pinto, N² ('Anaesthesiology resident; ${ }^{2}$ Anaesthesiology Fellow) Centro Hospitalar de Lisboa Ocidental, Portugal; Head of Department: Manuel Chedas

\section{Introduction:}

In some countries epidural analgesia is now the mainstay for controlling labour pain in appropriate patients ${ }^{1}$, but it is not devoid of risks (Table 1). Development of a cerebrospinal fluid-cutaneous fistula is a rare, often ill-known complication estimated to occur in 1:150.000 epidurals ${ }^{3}$, but one which should be promptly recognized as it entails a strong potential for infectious complications in the central nervous system.

\begin{tabular}{|c|ll}
$\begin{array}{c}\text { Complication } \\
\text { type }\end{array}$ & \multicolumn{1}{c}{ Specification } \\
\hline Related to & - & Inadvertent dural puncture \\
catheter insertion & - & Direct neurological damage \\
\hline Related to & - & Epidural haematoma \\
catheter presence & - & Epidural abcess \\
in situ & - & Catheter migration \\
& - & Drug error (type, dilution, formulation) \\
Related to & - & Respiratory depression \\
epidural drugs & - & CNS toxicity \\
& - & Unwanted motor block \\
\hline
\end{tabular}

Table 1 - Some complications derived from epidural analgesia (adapted from Nimmo 2004²).

Case report: 25 years old, 40 weeks 3 days pregnant ASA 2 patient, presenting to the hospital in labour. A lumbar epidural was sited at the L3-L4 interspace using the loss-of-resistance technique with saline. A test dose of 3cc levobupivacaine $0,2 \%$ was administered and 5 minutes later a further $3 \mathrm{cc}$, with the patient developing a patchy sensory block up to T8 with sacral sparing and patchy motor block, motivating the removal of the catheter and placement of a new one at the L4-L5 interspace. There was no haemodynamic instability. 4 hours later, the previously placed epidural catheter was used for the first time but was ineffective in relieving pain, which led a different, seasoned anaesthesiologist to place a new catheter at the L3-L4 level. However, it was soon realized that it was intrathecal, being removed, and a new one being inserted at the L2-L3 interspace. Several top ups were performed through this new catheter in the following 13,5 hours, with it ultimately being used for anaesthesia as the patient was submitted to caesarean section. 24 hours later the patient evidenced complaints suggestive of postdural puncture headache, which did not significantly improve with conservative measures in a further 24 hours. The epidural catheter was removed, but it soon became apparent that clear fluid oozed through the insertion site in the following hours. A fast glucose determination was made, evidencing a value of $92 \mathrm{mg} / \mathrm{dL}$, and Neurosurgical consultation was requested. A cerebrospinal fluidcutaneous fistula was assumed on clinical grounds (no MRI available) and indication for a blood patch decided by neurosurgery, which was performed at the L4-L5 interspace with administration of $17 \mathrm{cc}$ of autologous blood. The complaints immediately subsided, and the patient was discharged home 3 days later.

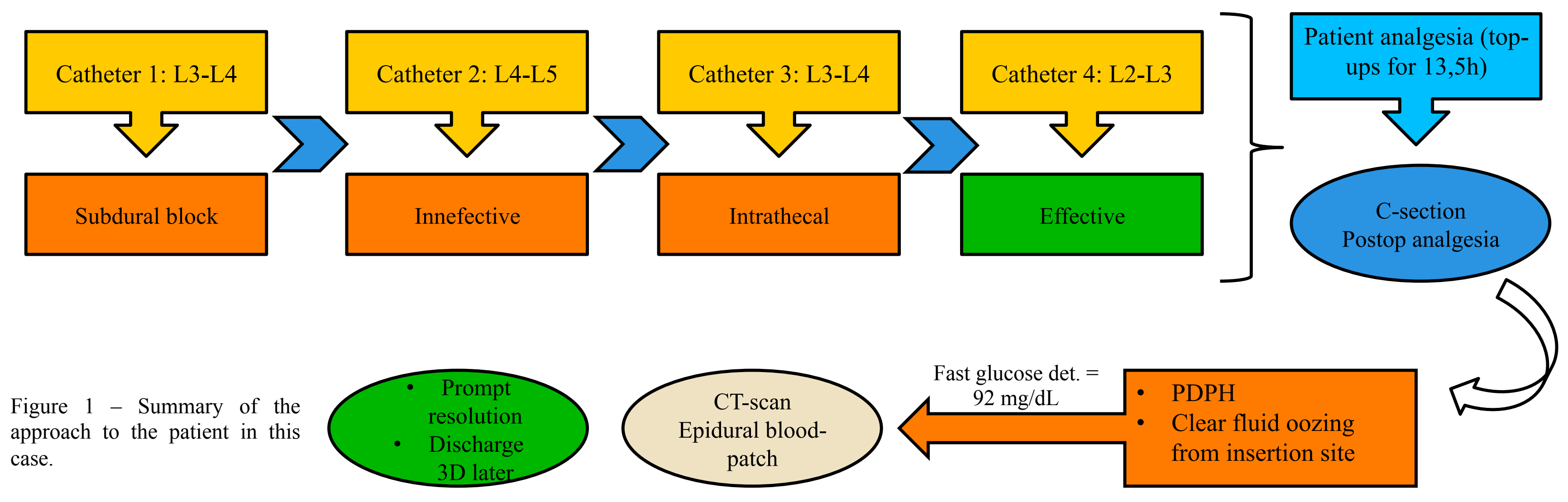

Discussion: CSF-cutaneous fistulas have been described as a complication of epidural placement, usually presenting in the first $24 \mathrm{~h}$ after catheter removal. They appear to be more frequent after multiple attempts at epidural placement, and constitute a risk factor for meningitis development $t^{4,5}$. Prompt assessment and treatment are therefore of utmost importance.

Neurosurgical consultation is advised, as in our case,

but first-line treatment usually consists of an epidural blood-patch. Consideration should also be given to antibioprophylaxis ${ }^{6}$.

Learning points: While epidural analgesia has several advantages, it should be faced with caution as the potential for severe complications is real and should be weighed in the decision making process. Importantly, multiple attempts at epidural catheter placement should be avoided.

\section{References}

1. McGrady E, Litchfield K. Epidural analgesia in labour. Contin Educ Anaesth Crit Care Pain. 2004;4:114-117.

2. Nimmo SM. Benefit and outcome after epidural analgesia: Table 1. Contin Educ Anaesth Crit Care Pain. 2004;4:44-47.

3. Salazar JAC, Ceballos EG, García GG, Suárez AM. Fístula cutánea de líquido cefalorraquídeo por catéter peridural. Revista Cubana de Anestesiología y Reanimación. 2010;9:218-222.

4. Abaza KT, Bogod DG. Cerebrospinal fluid-cutaneous fistula and pseudomonas meningitis complicating thoracic epidural analgesia. Br J Anaesth. 2004;92:429-431.

5. Howes J, Lenz R. Cerebrospinal fluid cutaneous fistula. Anaesthesia. 1994;49:221-222.

6. Sanches NPJ, Moro ET, Braz JRC, Nascimento PJ. Fístula Cutânea de Líquido Cefalorraquidiano. Uma complicação rara da anestesia peridural. Relato de caso. Rev Bras Anestesiol. 1996;46:130-132. 